\title{
Dexamethasone Suppression Test in Schizophrenia: Relationship to Symptomatology, Ventricular Enlargement, and Outcome
}

\author{
Rajiv Tandon, Cheryl Mazzara, John DeQuardo, \\ Katherine A. Craig, James H. Meador-Woodruff, \\ Robert Goldman, and John F. Greden
}

To relieve confusion abou: the clinical correlates and prognostic implications of the dexamethasone suppression test (DST) in schizophrenia, we conducted a DST in 44 schizophrenic inpatients at drug-free baseline and approximately 4 weeks after neuroleptic treatment. Patients were rated on positive, negative, and depressive symptoms at both times. A heac computed tomography (CT) scan was erformed and measures of ventriclebrain ratio (VBR) obtained. Clinical improvement was monitored at four weens, and longer-term outcome assessed at 1 year. Seventeen of the 44 patients were DST nonsuppressors at baseline, and five of these remained nonsuppressors at 4 weeks posttreatment. Postdexamethasone plasma cortisol levels were correlated with negative symptoms at baseline $(\mathrm{r}=0.45 ; \mathrm{p}<0.01)$, but not after 4 weeks of neuroleptic treatment. Postdexamethasone plasma cortisols were not related to global severity, positive, or depressive symptoms at either timepoint or to VBR. Persistent nonsuppression was associated with poor outcome, but baseline postdexamethasone cortisol levels were unrelated to outcome at 4 weeks and 1 year. The literature on DST in schizophrenia is reviewed and attempts are made to reconcile discrepant findings and to discuss pathophysiological implications.

\section{Introduction}

Aithough the dexamethasone suppression test (DST) was originally proposed as a specific marker for major depressive disorder (Carroll et al 1981), studies in schizophrenia have yielded rates of norsuppression ranging from $0 \%$ to $73 \%$ (Yeragani 1990). Higher rates of DST nonsuppression in schizophrenia have been attributed to depressive symptoras (Munro et al 1984; Sawyer and Jeffries 1984), negative symptoms (Coppen et al 1983; Shima et al 1986; Tandon et al 1989a), and the nonparanoid subtype (Banki et al 1984). It also has been suggested that DST nonsuppression in schizophrenia may prognosticate a better outcome (Targum 1983; Coryell and Zimmerman 1989). Most of these findings

Fron the Schizophrenia Program. University of Michigan Medical Center, Ann Arovor, Mt

Audress reprimt requests to Rajiv Tandon, M.D., Director, Schizophrenia Program. UH-9C-9150, University of Michigan Hospitals, Ann Arhor, Ml 48109-0120.

Received September 19. 1990; revised November 23, 1990. 
have not, however, been confirmed in other inve stigations and the approximately 50 studies of DST in schizophrenia have yielded discepant findings.

The present study was contucted in an effort to define the clinical correlates and prognostic implications of the LST response in s hizophrenia, and study the impact of phase of illness, neuroleptic treatment, and ventricular size. In a preliminary report (Tandon et al 1989a), we had observed a $35 \%$ nonsuppression rate in a sample of 20 medication-free schizophrenic patients, and an association between postdexamethasone cortisol levels and severity of negative symptoms. We now report findings on an expanded sample of 58 patients with regard to frequency of DST nonsuppression in medicationfre. and neuroleptic-treated phases of schizophrenic illness, and relationship of the DST response to symptomatology (positive, negative, and depressive symptoms). In this study, we additionally investigated the relationship of the DST response to ventricular size and 1-year outcome.

\section{Methods}

The original sample consisted of 58 consecutively hospitalized patients who were admitted to the Inpatient Schizophrenia Program at the University of Michigan from 1987-1989. All patients met DSM-HI-R (American Psychiatric Association 1987) and Research Diagnostic Criteria (RDC) (Spitzer et al 1978) for schizophrenia. Patients with any medical criteria known to interfere with a valid DST (Carrull et al 1981) were excluded. No patient had received depot neuroleptics for at least 6 months before entering the study. Informed consent was obtained. After patients had been drug-free for a minimum of 2 weeks, clinical ratings, head computed tomography (CT) scan, and a $1 \mathrm{mg}$ DST were performed. Patients were then treated with clinically determined doses of haloperidol, thiothixene, or chlorpromazine [doses of $8-30 \mathrm{mg}$ haloperidol equivalents per day (Baldessarini 1984)], singly or in combination with 2-6 mg of trihexyphenidyl. After about 4 weeks of such treatment, clinical ratings and the DST were repeated. Approximately 1 year after the initial drug-free evaluation, outcome was assessed. Outcome could be assessed on 44 of the 58 patients in the original sample. The remaining patients could not be located. All subjects who had clinical ratings and a valid DST at the drug-free and 4-week posttreatment timepoints, and on whom outcome conld be assessed at 1 year were included in the final sample. The final sample of 44 patients consisted of 29 men and 15 women, with a mean $( \pm S D)$ age of $29( \pm 8)$ years (range 18-46 years). The mean duration of the illness was 7 ( \pm 5 ) years. Of these 44 patients, 15 were drug naive (never medicated), 12 had been noncompliant with prescribed treatment and were drug free for $>4$ weeks, and 17 were drug free for $2-4$ weeks.

Patients were rated by one of the investigators (RT) on the 18-item Brief Fsychiatric Rating Scale [BPRS (Overall and Gorham 1962)], Scale for the Assessment of Negative Symptoms [SANS (Andreasen 1983)], and the Hamilton Depression Rating Scale [HDRS (Hamilton 1960)j ai baseline and about 4 weeks after neuroleptic treatment. Ratings were completed while blind to DST results and head CT findings. Global severity was assessed by the 18-item BPRS total score. Positive symptom severity was assessed by the sum of the following four BPRS items: conceptual disorganization, suspiciousness, hallucinatory behavior, and unusual thought content. Collectively, these items comprise the BPRS "THOT" factor (Guy 1976; Hedlund and Vieweg 1980) and are most commonly employed to rate positive symptoms. Negative symptoms were assessed by the SANS, the sum of 
giobal scores being employ ed as the measure of negative symprom severity. The BPRS "ANER" factor, consisting of emotional withdrawal, motor retardation, and blunted affect, was utilized for comparison. Depressive symptom severity was assessed by the 17-item HDRS total score. Change in symptom ratings at 4 weeks was employed as the measure of improvement at 4 wecks.

A 1-mg DST (Carroll et al 1981) was performed at drug-free baseline and after about 4 weeks of neuroleptic treatment. The first DST was performed at least 1 week after the patient's hospital admission to permit adaptation (Haskett et al 1989). Clinical ratings and the corresponding DST were performed within 2 davs, of each other. Blood samples for postdexamethasone cortisol levels were obcained at $4 \mathrm{PM}$ and $11 \mathrm{PM}$ and the naximal cortisol levels were employed for analysis. Curtisol was assayed by Murphy's competitive protein-binding method (Murphy 1967). Maxinal postdexamethasone cortisol levels > $5 \mu \mathrm{g} / \mathrm{dl}$ have been established in our clinical setting to be indicative of nonsuppression (Carroll et al 1981). Plasma dexamethasone levels were not measured in this study.

A head CT scan was performed on 36 of the 44 patients in the sample and measures of ventricle-brain ratio (VBR) obtained by videoscreen planimetry. Two raters (JD and JMW), blind to clinical ratings and DST findings, conducted these measurements and the mean of two ratings of the maximum VBR on the CT brain slices ( VVBR $_{\text {raax }}$ ) on each individual patient was employed for analysis.

Outcome was assessed by the Strauss-Carpenter scale (Strauss and Carpenter 1972; McGlashan 1984), on which hospitalization, employment, social activity, symptoms, Elobal function, and compliance are all assessed on a 5-point (0-4) scale. A family member/careprovider, and the individual's treating psychiatrist or community mental health center casemanager were contacted for this assessment by two independent raters (CM and $\mathrm{KC}$ ) about 1 year after the initial drug-free evaluation. After their independent assessments, a joint conference was held between these raters to arrive at final consensus ratings. The raters were blind to the clinical ratings, DST, and head CT findings.

The relationship between DST findings and other parameters was evaluated by calculating Pearson's product-moment correlations between log-transformed maximal pos:dexarivethasone cortisol levels and clinical ratings, VBR, and outcome measures. Based on DST suppression/nonsuppression at the two timepoints, patients were then divided into the following three groups: patients who were suppressive following dexamethasone at both timepoints (S-S); patients who were nonsuppressive at drug-free baseline but who converted to normal suppression after 4 weeks (NS-S); and those who continued to be nonsuppressors even after 4 weeks of neuroleptic treatment (NS-NS). These groups were compared on clinicar ratings, VBR, and outcome by analysis of variance (ANOVA).

\section{Results}

In the total sample, at drug-free baseline, postdexamethasone cortisol levels were significantly correlated with negative symptom scores measured either by the SANS ( $r=$ $0.45 ; n=44 ; p<0.01)$ or the BPFS "ANER" factor $(r=0.41 ; p<0.01)$. Figure 1 Wlustrates the relationship between baseline postdexamethasone cortisol and the SANS sum of global scores. Baseline postdexamethasone cortisol levels were significantly correlated to four SANS subscale global scores $(r=0.39-0.49 ; p<0.05$ for affective blunting, avolition-apathy, anhedonia-asociality, and attentional impairment) and showed a trend toward significant relationship with the alogia subscale global score $(r=0.31$; 


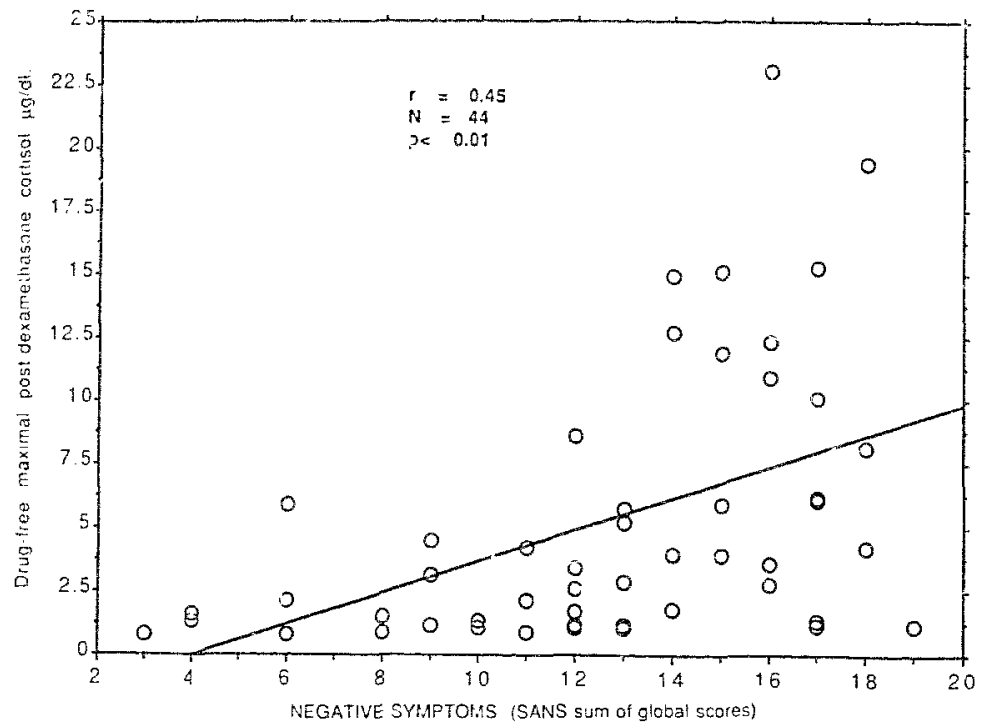

Figure 1. Association between postdex cortisol and negative symptoms $(r=0.45 ; n=44 ; p<$ $0.01)$.

$p<0.10)$. There was no relationship to global severity $(r=0.20 ; \mathrm{NS})$, positive symptoms $(r=0.20 ;$ NS), or depressive symptoms $(r=0.17$; NS). Similarly, baseline postdexamethasone coitisol levels were unrelated to age, sex, VBR, improvement of symptoms at 4 weeks, or any index of outcome at 1 year. (Similar indings were obtained when the larger sample of 58 patients, including 14 on whom outcome data not available, was considered.) : ostdexamethasone cortisol levels were significantly correlated to change in SANS sum of giobal scores during neuroleptic treatment $(r=0.38 ; p<0.05)$.

At the 4-weel posttreatment timepoint, postdexamethasone cortisol levels were unrelated to negative symptoms $(r=0.13$; NS), positive symptoms $(r=0.15$; NS), depressive symptoms ( $r=0.13$; NS), or global severity $(r=0.23$; NS). There also was no asscciation with age, sex, VBR, or outcome at 1 year. Drug-free and 4-week posttreatment postdexamethasone cortisol levels were significantly correlated $(r=0.42$; $p<0.01$ ).

The BPRS total (mean \pm SD) ot the entire sample at rnedication-free baseline was 49 ( \pm 7.5 ). The mean severity of positive symptoms (measured by the BPRS "THOT" subscale) and negative symptorns (measured by the SANS sum of global scores) were $15.7( \pm 3.0)$ and $13.2( \pm 3.9)$ respectively. Both positive and negative symptoms improved with neuroleptic treatment; the mean positive and negative symptom severity at 4-weeks postreatment were $9.5( \pm 3.1)$ and $8.8( \pm 3.9)$ respectively. The mean maximal postdexamethasone cortisol was $5.5( \pm 5.0)$ at drug-free baseline and $2.6( \pm 2.6)$ at 4weeks posttreatment. Head $C T$ scans from 36 patients resulted in a mean $\pm S D L V B R_{\max }$ of $0.08( \pm 0.03)$. 
Seventeen of the 44 patients ( $39 \%$ ) were DST noisuppressors at baseline, including five of 15 previously never-medicated patients. in the larger sample of 58 patients, 22 were nonsuppressors, yielding a similar nonsuppression rate of $38 \%$ at drug-fres baseline. Although all paiients were drug-free for at least 2 weeks before the initial DST, Kraus et al (1988) have suggested that withdrawal of neuroleptics-anticholinergics may produce DST nonsuppression lasting up to 21 days. Analysis of the cata to examine for this possibility revealed that in our final sample, 15 patients were drug naive, 12 patients were drug free $>4$ weeks, and 17 patients were drug free for 2-4 weeks. Five of the 15 drug-naive patients $(33 \%)$, five of the 12 patients orug free $>4$ weeks $(42 \%)$, and seven of the 17 patients drug free for 2-4 weeks (41\%) were DST nonsuppressors. Thus, psychotropic withdrawal effects apparently did not account for the DST findings observed in our study.

Of the 17 baseline DST nonsuppressors 12 became normally suppressive (NS-S) at 4weeks postcreatment. $G_{i}$ the 27 patients who were DST suppressors at drug-free baseline, 26 remained suppressive (S-S), while one became a DST nonsuppressor at 4-weeks posttreatment. This patient was classified with the five persistent DST norsuppressors in the NS-NS group. The three groups are compared on symptom ratings, VBR, and outcome in Table 1. The three groups did not differ in age or sex $c$ siribution. While there was no statistical difference in maximal VBR between the three groups, persistent DST nonsuppressors tended to have larger VBR $(F=1.8$; $\mathrm{df}=2,33 ; p<0.19)$.

At drug-free baseline, the three groups did not differ with regara to severity of positive symptoms, depression, or global severity. Both persistent DST nonsuppressors and normalizing DST nonsuppressors had significantly higher negative symptom scores than the persistcnt DST suppressor group. By definition, both the DST nonsuppressor groups had significantly higher postdexamethasone cortisol levels than the DST suppressor group.

After 4 weeks of clinically determined neuroleptic treatment, the three groups did not differ with regard to severity of positive symptoms, depression, or global severity. The persistent DST nonsuporessor group had significantly higher negative symptom ratings than the persistent DST suppressor and normalizing DST nonsuppressor (suppressor at this timepoint) groups. Again by definition, the persisten DST nonsuppressor group had higher mean postdexamethasone cortisol than the other two groups.

After 4 weeks of neuroleptic treatment, the normalizing DST nonsuppressor group showed significantly greater improvement in both negative symptoms and global severiy than the other two groups. There were no differences between the three groups with regard to degree of improvement of positive or depressive symptoms.

There were significant differences between the three groups with regard to l-year outcome. The persistent DST nonsuppressor group had significantly worse wtal outcome than the other two groups. While the normalizing DST nonsuppre ar group had somewhat butter ostcome than the persistent DST suppressor group, this diurence was not statis. ti ally significant. The three groups did not differ with regard to treatment complance.

Discussion

Thirty-nine percent (17 of 44) of schizophrenic patients vere DST nonsuppressors at medication-free baseline. Four weeks after neuroleptic treatment, $14 \%(6$ of 44$)$ of these patients remained DST nonsuppressors. The rate of DST nonsuppression observed in our sample is intermediate between the $0 \% 1073 \%$ reported in the literature and is comparable to data reported in most recent studies (Table 2). All studies of the 1 -mg DST in schizophrenia (not schizoaffective disorder) with a sample size $>10$, when employed a post- 
Table 1. Comparison of Persistent DST Suppressors, Persistent DST Nonsuppressors, and DST Nonsuppressors Convertine to Suppressor Status with Four Weeks Neuroleptic Treatment

\begin{tabular}{|c|c|c|c|c|}
\hline Parameter & $\begin{array}{c}\text { Persistent DST } \\
\text { suppressors } \\
\text { (S-S) } n=26\end{array}$ & $\begin{array}{c}\text { Normalizing DST } \\
\text { nonsuppressors } \\
\text { (NS-S) } n=12\end{array}$ & $\begin{array}{l}\text { Persistent DST } \\
\text { nonsuppressors } \\
\text { (NS-NS) } n=6\end{array}$ & $\begin{array}{c}\text { Significance } \\
\text { (ANOVA) }\end{array}$ \\
\hline Age & $27 \pm 8$ & $32 \pm 8$ & $31 \pm 7$ & NS \\
\hline Sex $(M / F)$ & $18 \mathrm{M} / 8 \mathrm{~F}$ & $7 \mathrm{M} / 5 \mathrm{~F}$ & $4 \mathrm{M} / 2 \mathrm{~F}$ & NS \\
\hline VBR & $0.077 \pm 0.03$ & $0.080 \pm 0.03$ & $0.097 \pm 0.05$ & NS \\
\hline \multicolumn{5}{|l|}{ Medication-free } \\
\hline Positive (BPRS “THOT”) & $15.3 \pm 3.0$ & $16.5 \pm 3.4$ & $15.8 \pm 1.0$ & NS \\
\hline Negative (SANS glob sum) & $11.7 \pm 4.2$ & $15.1 \pm 2.0$ & $15.5 \pm 1.9$ & $F=5.2 ; p<0.01$ \\
\hline Depression (HRSD tot) & $13.1 \pm 4.8$ & $13.4 \pm 2.7$ & $12.3 \pm 3.4$ & NS \\
\hline Global severity (BPRS tot) & $48.2 \pm 7.4$ & $50.5 \pm 9.0$ & $49.0 \pm 4.7$ & NS \\
\hline Post-dex cortisol $\mu \mathrm{g} / \mathrm{d}]$ & $2.4 \pm 1.3$ & $10.0 \pm 4.7$ & $12.8 \pm 6.8$ & $p<0.001$ \\
\hline \multicolumn{5}{|l|}{ Fontr-weeks posttre atment } \\
\hline Positive & $9.6 \pm 3.1$ & $8.8 \pm 2.9$ & $10.2 \pm 3.8$ & NS \\
\hline Negative & $8.3 \pm 4.0$ & $8.8 \pm 3.0$ & $12.0 \pm 2.7$ & $F=3.3 ; p<0.05$ \\
\hline Depression & $7.0 \pm 3.5$ & $6.9 \pm 2.4$ & $6.7 \pm 3.5$ & NS \\
\hline Global severity & $35.5 \pm 7.1$ & $32.8 \pm 5.9$ & $37.7 \pm 6.7$ & NS \\
\hline Post-dex cortisol & $1.8 \pm 0.8$ & $1.8 \pm 0.8$ & $8.7 \pm 3.2$ & $p<0.001$ \\
\hline \multicolumn{5}{|l|}{ Change in symptoms 4 weeks } \\
\hline Positive & $5.7 \pm 3.3$ & $7.7 \pm 4.7$ & $5.7 \pm 3.4$ & $\mathrm{NS}$ \\
\hline Negative & $3.4 \pm 2.0$ & $6.3=2.6$ & $3.5 \pm 2.6$ & $F=6.5 ; p<0.01$ \\
\hline Depression & $5.7 \pm 2.4$ & $6.6 \pm 1.7$ & $5.7 \pm 2.5$ & NS \\
\hline Global severity & $12.7 \pm 6.8$ & $17.7 \pm 6.5$ & $11.3 \pm 5.2$ & $F=3.3 ; p<0.05$ \\
\hline \multicolumn{5}{|l|}{ One-year outcome } \\
\hline Hospitalization & $3.6 \pm 0.8$ & $3.9 \pm 0.3$ & $3.3 \pm 0.8$ & NS \\
\hline Employment & $1.7 \pm 1.2$ & $1.9 \pm 0.9$ & $i .0 \pm 0.9$ & NS \\
\hline Social activity & $2.3 \pm 1.4$ & $2.8 \pm 1.5$ & $2.0 \pm 1.4$ & NS \\
\hline Symptons & $2.1 \pm 1.0$ & $2.0 \pm 0.8$ & $1.3 \pm 0.8$ & NS \\
\hline Global function & $2.4 \pm 1.1$ & $2.7 \pm 1.1$ & $1.6 \pm 0.9$ & NS \\
\hline Total & $12.1 \pm 2.0$ & $13.3 \pm 2.1$ & $9.2 \pm 1.7$ & $F=3.5 ; p<0.05$ \\
\hline Compliance & $3.2 \pm 1.1$ & $3.1 \pm 3.4$ & $3.5 \pm 0.8$ & NS \\
\hline
\end{tabular}

dexamethasone cortiso! value of $5 \mathrm{ing} / \mathrm{dl}$ as the cutoff for nonsulpression are enumerated in this table. A summary meta-analysis of these studies reveali; a DST nonsuppression rate of $36 \%$ in the drug-free state (39\% in our sample) and $20 \%$ in the medicated state (14\% in our sample). These data suggest that phase of lllnes: and medication status infuence rates of DST nonsumpression in schizophrenia and $\mathrm{m}$ partially account for the discrepart findings in the uterature. Rates of DST nonsuppression are higher in drugfree schizophrenic patients in the acute phase of the illness. The significant reduction in rates of DST non uppression that we observed after 3-4 weeks of neuroleptic treatment is consistent with this suggestion and with findings of other studies in which the DST was rerformed before and after neuroleptic treatment (Herz et al 1985; Holsboer-Trachsler et al 1987; Moller et al 1986; Tandon et al 1989a; Wik et al 1986).

The association between postdexamethasone cortisol levels and severity of neguive symptoms observed in our study is in agreement with eight of the 12 other studies that evaluated this association (refer to Table 2). We observed an association between postdexamethasone cortisol and negative symptoms in the drug-free state, but not after 3-4 weeks of neuroleptic treatment. These findings are similar to those of the Stanford group, 
Table 2. Dexamethasone Sippression Test in Schizophrenia: Rates of Nonsuppression, Association with Symptomatelogy, Medication Status, and Outcome

\begin{tabular}{|c|c|c|c|c|c|}
\hline \multirow[b]{2}{*}{ Study } & \multicolumn{2}{|c|}{ Nonsuppression rate } & \multicolumn{2}{|c|}{ Associations } & \multirow[b]{2}{*}{ Outcome } \\
\hline & Med. free & Medicated & Negati'e & Depression & \\
\hline Addington and Addington 1990 & - & $6 / 50(12 \%)$ & No & Yes & - \\
\hline Aleem et al 1988 & - & $6 / 19(32 \%)$ & 一 & No & - \\
\hline Altamura et al 1989 & - & $22 / 54(40 \%)$ & Yes & - & - \\
\hline Asnis et a! 1986 & $4 / 17(24 \%)$ & - & - & - & - \\
\hline Banki et al 1984 & $19 / 45(42 \%)$ & - & - & - & - \\
\hline Banki et al 1986 & $7 / 20(35 \%)$ & - & - & - & - \\
\hline Baumgartner et al 1984 & $11 / 22(50 \%)$ & - & - & - & - \\
\hline Berger et al 1984 & - & $4 / 21(19 \%)$ & - & - & - \\
\hline Castro et al 1983 & 一 & $7 / 23(30 \%)$ & - & - & - \\
\hline Coppen et al 1983 & - & $10 / 46(22 \%)$ & Yes & - & - \\
\hline Coryell and Zimmerman 1989 & - & $8 / 31(26 \%)$ & - & - & good 1-year outcome \\
\hline Dan et al 1985 & - & $5 / 15(33 \%)$ & - & $-\infty$ & - \\
\hline Dewan et al 1982 & - & $6 / 20(30 \%)$ & - & No & - \\
\hline Doran et al 1.986 & $2 / 13(16 \%)$ & - & - & No & - \\
\hline Faustman et al 1990 & $7 / 21(33 \%)$ & - & Yes & No & - \\
\hline Cold et al 1981 & - & $0 / 25(0 \%)$ & - & - & - \\
\hline Fiarris 1985 & - & $4 / 12(33 \%)$ & Yes & - & - \\
\hline Herz et al 1985 & $11 / 15(73 \%)$ & $1 / 5(20 \%)$ & - & - & - \\
\hline Holsboer-Trachsier et al 1987 & $15 / 31(48 \%)$ & $4 / 31(13 \%)$ & - & - & not related: 4 weeks \\
\hline Hubain et at 1986 & $10 / 22(45 \%)$ & - & - & - & - \\
\hline Hwang et al 1984 & - & $2 / 13(15 \%)$ & - & - & - \\
\hline Jones et al 1990 & $6 / 17(35 \%)$ & - & No & Yes & - \\
\hline Joseph et al 1987 & - & $2 / 39(5 \%)$ & - & - & - \\
\hline Keshavan et al 1989 & $3 / 27(11 \%)$ & 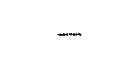 & No & Wo & $\begin{array}{l}\text { worse outcome; } 4 \\
\text { weeks }\end{array}$ \\
\hline Kiriike et al 1988 & - & $2 / 22(9 \%)$ & - & - & - \\
\hline Krishnan et al 1987 & - & $2 / 15(13 \%)$ & - & No & - \\
\hline McGauley et al 1989 & - & $4 / 28(14 \%)$ & Yes & No & - \\
\hline McMahon et al 1986 & - & $2 / 12(17 \%)$ & - & $一$ & - \\
\hline Mellsop et al 1985 & $6 / 30(20 \%)$ & - & - & - & - \\
\hline Moller et al 1986 & $12 / 20(60 \%)$ & $6 / 13\{6 \%)$ & - & - & - \\
\hline Morphy et al 1985 & - & $6 / 13(46 \%)$ & - & - & - \\
\hline Munro et al 1984 & - & $7 / 46(15 \%)$ & - & Yes & - \\
\hline Nelson et al 1984 & - & $4 / 14(29 \%)$ & - & - & - \\
\hline Nishimon et al 1984 & - & $16 / 67(25 \%)$ & - & - & - \\
\hline Pandey et al 1987 & $4 / 22(18 \%)$ & - & - & - & - \\
\hline Perenyi et al 1987 & - & $6 / 30(20 \%)$ & - & No & - \\
\hline Rihmer and Arato 1984 & - & $1 / 20(5 \%)$ & - & - & - \\
\hline Rothschild et al 1982 & - & $2 / 14(14 \%)$ & - & - & - \\
\hline Saffer et al 1985 & - & $10 / 50(20 \%)$ & Yes & No & - \\
\hline Sawyer and Jeffries 1984 & - & $7 / 20(35 \%)$ & - & Yes/No & - \\
\hline Schlesser et al 1780 & $\ldots$ & $0 / 48(00)$ & - & - & 一 \\
\hline Shama et al 1988 & $8 / 44118 \%$ & - & - & No & - \\
\hline Shima et al 1986 & - & $5 / 22(23 \%)$ & Yes & No & - \\
\hline Siris et al 1284 & - & $0 / 16(0 \%)$ & - & - & - \\
\hline Sora et al 1986 & - & $7 / 28(25 \%)$ & - & - & - \\
\hline Stokes et al 1984 & $2 / 12(17 \%)$ & - & - & - & - \\
\hline Tandon et al 1989 & $7 / 20(35 \%)$ & $n / 20(0 \%)$ & Yes & No & $\begin{array}{l}\text { Evod outcome. } 4 \\
\text { weeks }\end{array}$ \\
\hline Targum 1983 & $5 / 21(24 \%)$ & - & - & - & $\begin{array}{l}\text { good outcome } \\
\text { months }\end{array}$ \\
\hline Whiteford et ai 1988 & - & $9 / 40(23 \%)$ & No & No & - \\
\hline Wik et al 1986 & $15 / 21(71 \%)$ & $3 / 15(20 \%)$ & - & - & - \\
\hline Wolkowitz et al 1989 & $4 / 16(25 \%)$ & - & - & - & 一 \\
\hline Zhou et al $198 ?$ & - & $6 / 48(13 \%)$ & - & - & - \\
\hline
\end{tabular}


who observed no relationship between postdexamethasone cortisol and negative symptoms in chronic, medicated schizophrenic patients (Whiteford et al 1988), but observed such a relationship in acute, unmedicated patients (Faustman et al 1990). These data, in addition to the association between postdexamethasone cortisol levels and change in negative symptoms observed in our study, may indicate that in the acute phase of the illness, postdexamethasone cortisol levels are related to nonenduring negative symptoms (Carpenter et al 1988; Tandon et al 1990; Tandon and Greden 1990a).

Our failure to find any association between postdexamethasone cortisol and depressive symptons is consistent with the findings of 13 of the 17 studies that assessed this association (refer to Table 2). Despite the phenomenological overlap between negative and depressive symptoms and consequent difficulty in differentiating between them (Sommers 1985; Addington and Addington 1990), recent studies indicate that these phenomena can be distinctly measured in schizophrenia (Barnes et al 1989; Newcomer et al 1990; Liberzon et al 1990). Our finding of an association between postdexamethasone cortisol levels and negative symptoms, but not with depressive symptoms, would support this contention. We found no other relationship between postdexamethasone cortisol and global severity, a finding consistent with other studies that evaluated this association (Dewan et al 1982; Shima et al 1986; Tandon et al 1989a).

The observer relationship between DST findings and outcome was complex, Baseline postdexamethasone cortisol itself was unrelated to outcome at 4 weeks or 1 year. The pattern of baseline DST nonsuppression converting to normal suppression after 4 weeks of neuroleptic treatment was associated with significantly greater improventent in both negative symptoms and global severity at 4 weeks; this finding is consistent with our previous finding (Tandon et al 1989a) and those of Holsboer-Trachsler et al (1987). Conversely, persistent DST nonsuppressicn was associated with greater negative symptom severity at 4 weeks and poor outcome at 1 year. These findings parallel those in major depression, where normalizing baseline DST nonsuppression is associated with greater clinical improvement (Greden et al 1983; Brown and Qualls 1981; Baldessainini and Arana 1985), and persistent DST nonsuppression is associated with poor outcome (Greden et al 1983; Baldessarini and Arana 1985).

Our findings appear to be at variance with those of Coryell and Zimmerman (1989); they observed an association between baseline DST nonsuppression and good 1-year outcome in functional psychosis, including schizophrenia. The following methodological differences may have contributed to this discrepancy: (1) in their study, the baseline DST was not always performed under drug-free conditions; (2) the association between postdexamethasone cortisol levels and good I-year outcome noted in their study was somewhat equivocal with regard to the schizophrenic group (Tandon et al 1989b), and (3) because they were studying the association of baseline drug-free DST, their group of initial DST nonsuppressors included both normalizing nonsuppressors (associated with better 4-week outcome in our study) and persistent DS1 nonsuppressors (associated with worse 1-year outcome in our study).

Pathophysiological mechanisms that may underly these phenomena are not known. Normalizing DST nonsuppression may be related to stress, cholinergic hyperactivity (Carroll et a! 1980; Tandon and Greden 1989, 1990b), or some other mechanism associated with better resolution of the index psychotic episode. The association between negative symptoms and postdexamethasone cortisol at drug-free baseline, but not at 4-weeks posttreatment is consistent with this suggestion (Tandon and Greden 1989, 1990b). The greater improvement in negative symptoms with $3-4$ weeks of neuroleptic treatment in the normalizing DST nonsuppressor group and other data indicating that postdexamethasone cortisol levels 
are related to nonenduing negative symptoms in the acute phase would also support this hypothesis. On the other hand, persistent DST nonsuppression may be related to some other mechanism (such as enlarged ventricles, Rothschild et al 1989) that may be associated with poor outcome (Coppen et al 1983). In the present study, the persistent DST nonsuppressor group tended to have gieater VBR (although this difference was not statistically significant, perhaps reiated to the small number of patients in this group, $n=6$ ) and poor 1-year outcome. However, these explanations remain speculative.

In summary, a significant proportion of schizophrenic patients exhibit abnormal feedback regulation in the hypothalamic-pituitary-adrenal axis, as reflected in DST nonsuppression. A greater proportion of schizophrenic patients exhibit DST nonsuppression in the medication-free phase than in the neuroleptic-treated phase. There is a significant association between postdexamethasone cortisol and severity of negative symptoms, particularly in the drug-free phase. There appears to be no association between DST findings in schizophrenia and severity of depressive symptoms. Normalizing DST nonsuppression appears to be associated with greater clinical improvement with neuroleptic treatment. Persistent DST nonsuppression appears to be associated with worse outcome. While disinict mechanisms may underlie these phenomena, the pathophysiological bases of DST nonsuppressiún in schizophrenia remain unclear. Future studies should take medication status and phase of illness into consideration, as these appear to be important confounding variables.

Supported in part by grants from the National Alliance for Schizophentia and Deptession (NARSAD) and NIH \#M01 RR00042.

\section{References}

Addington D, Addington I (1990): Depression, dexamethasone nonsippression, and negative symptoms in schizophrenia. Can $f$ Psychiatry 35:430-433.

Aleem A, Kulkami A, Yeragani VK (1988): Dexamethasone suppression test, schizophrenia, and movement disorder. Acta Psychiatrica Scandinavica 78:689-694.

Altamura C. Guercetti G, Percudani M (1989): Dexamethasone suppression test in positive and negative schizophrenia. Psychiatry Res 30:69-75.

American Psychiatric Association (1987): Diagnostic an Statistical Manual of Menal Disorders, 3rd ed rov. Washington, DC: American Psychiatric Association.

Andreasen MC (1983): Scale for the Assessment of Negative Symptoms (SANS). Iowa City, Iowa, University of lowa Press.

Baldessarini RJ (1984): Antipsychotic agents. In Karasu B (ed), Psychiatric Therapies. Washington, DC: American Psychiatric Association, pp 119-170.

Baldessarini $\mathrm{R}_{\mathrm{W}}$, Arana GW (1985): Does the dexamethasone suppression test have clinical utility in psychiatry? J Clin Psychiatry 46:25-29.

Banki CM. Afato M, Rihmer Z (1984): Neuroendocrine differences among subtypes of schizophrenic disorder. Neuropsychobiology 11:174-177.

Banki CM, Arato M, Papp Z, Ribmer Z, Kovacs Z (1986): Associations among dexamethasone non-suppression and TRH-induced hormonal responses: Increased specificity for melancholia, Psychoneuroendocrinology 11:205-211.

Bames TRE, Curson DA, Liddle PF, Patel M (1989): The nature of prevalence of depression in chronc schizophrenic inpatients. Br J Psychiary 154:486-491.

Baumgartzer A, Graf K-J, Kurten I (1985): The dexamethasone suppression test in depression, in schizophrenia, and during experimental stress. Biol Psychiatry 20:675-679.

Berger $M$, Pirke K-M, Doerr P, Krieg J-C, von Zerssen D (1984): The limited utility of the dexamethasone suppression test for the diagnostic process in psychiatry. Br J Prvchiatry 145:37238 . 
Brown WA, Qualls CB (1981): Pituitary-adrenal disinhibition in depression: Marker of a subtype with characteristic clinical features and response to treatment? Psychiatry Res 4:115-128.

Carpenter WT Jr, Heinrichs DW, Wagman AMI (1988): Deficit and nondeficit forms of schizophrenia: The concept. Am I Psychiatry 145:578-583.

Carroll BJ, Greden JF, Haskett RF, et al (1980): Neurotransmitter studies of neuroendocrine pathology in depression. Acta Psychiatr Scand 61(Suppl 280):183-189.

Carroll BJ, Feinberg M, Greden JE, et al (1981): A specific laboratory test for the diagnosis of melancholia. Standardization, validation, and clinical utility. Arch Gen Psychiatry 38:15-22.

Castro P, Lenaire M, Toscano-Aguilar M, Herchuelz A (1983): Abnormal DST results in patients with chronic schizophrenia. Am J Psychiatry 140:1261.

Coppen A, Abou-Saleh M, Milln P, Metcalfe M, Harwood J, Bailey J (1983): Dexamethasone suppression test in depression and other psychiatric illness. Br J Psychiatry 142:498-504.

Coryeil WH, Zimmerman M (1989): HFA axis reactivity and recovery from functional psychosis. Am J Psychiatry 146:473-477.

Dam H, Mellerup ET, Rafaelson OJ (1985): The dexamethasone suppression test in depression. $J$ Affective Disord 8:95-103.

Dewan MJ, Pandurangi AK, Boucher ML, Levy B, Major P (1982): Abnormal dexamathasone suppression test results in chronic schizophrenic patients. Am J Psychiatry 135:1501-1503.

Doran A, Rubinow D, Roy A, Pickar D (1986): CSF somatostatin and abnormal response to dexamethasone administration in schizophrenic and depressed patients. Arch Gen Psychiatry 43:365-370.

Faustman WO, Whiteford HA, Newcomer JW, Csernansky JG (1990): Negative and positive symptoms correlate with post-dexamethasone cortisol in unmedicated schizophrenics. Biol Psychiatry 27:169A.

Gold MS, Pottash ALC, Extein 1, Sweeney DR (1981): Diagnosis of depression in the 1980s. JAMA 245:1562-1564.

Greden JF, Gardner R, King D, et al (1983): Dexamethasone suppression tests in antidepressant treatmeni of melancholia. Arch Gen Pychiatry 40:493-500.

Guy W (1976): ECDEU Assessment Manual for Psychopharmacology (DHEW publication no. 76338). Rockville, MD: National Institute of Mental Health.

Hamilton M (1960): Development of a scale for primary depressive illness. Br J Soc Clin Psychol 6:278-295.

Harris VJ (1985): The dexamethasone suppression test and residual schizophrenia. Am J Psychiatry 142:659-660.

Haskett RF, Zis AP, Albala AA, et al (1939): Comparison of early and delayed inpatient dexamethasone suppression tests. Psychiatry Res 27:161-171.

Hedlund JL, Vieweg BW (1980): The Brief Psychiatric Rating Scale (BPRS): A comprehensive review. $J$ Operational Psychiatry 11:48-65.

Herz MI, Fava GA, Molnar G, Edwards L. (1985): The dexamethasone suppression test in newly hospitalized schizophrenic patients. Am. J Psychiatry 142:127-129.

Holsboer-Trachsler E, Buol C, Wiedemann $K$, Holsboer $F$ (1987): Dexamethasone suppression test in severe schizophrenic illness: Effects of plasma dexamethasone and caffeine levels. Acta Psychiatr Scand 75:608-613.

Hubain PP, Simonnet MP, Mendlewicz J (1986): The dexamethasone suppression test in affective illnesses and schizophrenia: Relationship with psychodic symptoms. Neuropsychot ology 16:5760.

Hwang S, Zander J, Garvey M (1984): Dexamethasone suppression tegi: Use of two different dexamethasone doses $J$ Clin Psychiatry 45:390-392.

Jones JS, Stanley B, Guido J, Winchel R, Stanley M (1990): Suicidal behavior in schizophrenia. Biol Psychiatry 27:121a. 
Joseph S, Kulhara P, Dash RJ (1987): Dexamethasone suppression test in schizophrenic patients: Report from India. Biol Psychiatry 22:792-795.

Keshavan MS, Brar J, Ganguli R, Jarret D (1989): DST and schizophrenic symptomatology. Biol Psychiatry 26:856-858.

Kiriike N, Izumiya S, Nishiwaki S, Maeda Y, Nagata T, Kawakita Y (1988): TRH test and DST in schizoaffective mania, mania, and schizophrenia. Biol Psychiatry 24:415-422.

Kraus RF, Graf P, Brown M (1988). Drugs and the DST: Need for a reappraisal. Am I Psychiatry 145:666-674.

Krishnan KRR, David J, Rayasam K, Tanas KS, Shope FS, Pelton S (1987): Diagnostic utility of the dexamethasone suppression test. Biol Psychiotry 22:618-628.

Liberzon I, Goldman R, Tandon R (1990): Assessment of depression in schizophrenia. Abstracts of the American Psychiatric Association, 143rd annual meeting. NK 116, New York.

McGauley GA, Aldridge CR, Fahy TA. Eastment C (1989): The dexamethasone suppression test and negative symptoms of schizophrenia. Acta Psychiatr Scand 80:548-553.

McGlashan TH (1984): The Chesinut Lodge follow-up study: Follow-up methodology and study sample. Arch Gen Psychiatry 41:573-585.

McMahon T, Malek-Ahmadi P, Ainslie J (1986): DST in chronic schizophrenia, Biol Psychiatry $21: 570-571$.

Mellsop GW, Cooke RR, Vijayasenan ME (1985): The diagnostic distribution of dexamethasone nonsuppressors. Austr NZ J Psychiatry 19:168-171.

Moller HJ, Kissling W, Bottermann P (1986): The dexamethasone suppression test in trpressive and schizophrenic patients under controlled treatment conditions. Eur Arch Psychatry Neur al Sci 235:263-268.

Morphy MA, Fava GA, Carson SW, Perini GI, Molnar G, Jusko WJ (1985): The metyratione test in schizophrenic patients and heaithy subjects. Neuropsychobiology 14:35-38.

Munro JG, Hardiker TM, Leonard DP (1984): The dexamethasone suppression test in residuat schizophrenia with depression. Am I Psychiary 141:250-252.

Murphy BE (1967): Some stidies of the protein-binding of steroids and their application to the routine micro- and ultra-micro measurement of various steroids in body fuids by competitive protein-binding radioassay. J Clin Endocrinol Metab 27:973-990.

Nelson WH, Khan A, Or WW, Tamragouri RN (1994): The dexamethasone suppression test: Interaction of diagnosis, sex, and age in psychiatric inpatients. Riol Psychiatry 19:1293-1304.

Newcomer JW, Faustman WO, Yeh W, Csemansky JG (1990): Distinguishing depressive and negative symptoms in unmedicated patients with schizophrenia. Psychiatry Res $31: 243-250$.

Nistimon K, Sora 1, Sato M, Otsuki S (1984): Clinical relevarice of dexamethasone suppression test (DST) in affective and schizophrenic disorders. Anni Rep Phamacopsychiarn Res Found $15: 256-262$.

Overall JE, Gorham DR (1462): Brief Psychiatric Rating Scale. Psychol Rep 10:799-812.

Pandey GN, Janicak PG, Davis JM (1987): Decreased beta-adrenergic receptors in the lewkocytes of depressed patients. Psychiaty Res 22:265-273.

Perenyi A, Frecs;a E, Rimmer Z. Arato M (1987): Dexamethasone suppression test and depressive symptoms in schizophrenies and endogenous depressed patients. Fharmacopsychiatry 20:4850 .

Rihmer Z, Arato M (1984): The DST as a clinical aid and research tool in patients with affective disorder. Psychopharmacol Buil 20:174-177.

Rothschild AJ, Schatzberg AF, Rosenbaum AH, Stahl JB, Cole JO (1982): The dexamethasone supprersion test is a discriminator among subtypes of psychotic patients. Br I Psychiatry $141: 471-474$.

Rothschild AJ, Benes $F$, Hebben $N$, et al (1989): Relationship between brain CT sean findings and cortisol in psychotic and nonpychotic depressed patients. Biol Psychiary $26: 565-575$. 
Saffer D, Metcalfe M, Coppen A (1985): Abnormal dexamethasone suppression test in type II schizophrenia. Br J Psychiatry 147:721-723.

Sawyer J, Jeffries $1 /$ (1984): The dexamethasone suppression test in schizophrenia. J Clin $p_{\text {sychiary }}$ 45:399-402.

Schesser MA, Winokur G. Sherman BM (1980): Hypothalamic-pituitary-adrenal axis activity in depressive illness. Arch Gen Psychiatry 37:737-743.

Sharma RP, Pandey GN, Janicak PG (1988): The effect of diagnosis and age on the DST: A metaanalytic approach. Biol Psychiaily 24:555-568

Shima S, Kitamura $T$, Takahashi $Y$, Asai $M$ (1986): Dexamethasone suppression test and negative symptoms of schizephrenics. Keio J Med 35:203-207.

Siris SG. Rifkin A. Reardon GT, et al (1984): The dexamethasone suppression test in patients with posipsychotic depressions. Biol Fsychiatry 19:1351-1356.

Sonmers A (1985): "Negative symptoms": Conceptual and methodological problems. Schizophr Bull 11:364-379.

Sora I, Nishinon $K$, Otsuki S (1986): Dexamethasone suppression teet and noradrenergic function in affective and schizophrenic disorders. Biol Psychiatry 21:621-531.

Spizer RL, Endicott J, Robins E (1978): Research Diagnostic Criteria: Rationale and reliability. Arch Gen Psychiany 35:773-782.

Sicies PE, Stoll FM, Koslow SH, et al (1984): Pretreatment DST and hypothalamic-pituitayadrenocortical function in depressed patients and comparison groups, Arch Gen Psychiamy $41: 257-267$.

Strauss IS, Carpenter WT (1972): The prediction of outcome in schizophrenia: I. Characteristics of outcome. Arch Gen Fsychiatry 27:739-746.

Tandon R, Greden JF (1989): Cholinergic hyperactivity and negative schizophrenic symptoms: A model of cholinergic/dopaminergic interactions in schizophrenia. Arch Gen Psychiatry 46:745753.

Tandon R, Greden JF (1990a): In conclusion: Is integration pessible? In Greden JF, Tandon $R$ (eds), Negative schizophrenic symptoms: Pathophysiology and clinical implications. Washington, DC: American Psychiatric Press, pp 235-239.

Tandon R, Greden JF (1990b): Cholinergic excess and the negative schizophrenic syndrome. In Greden JF, Tandon R (eds), Negative schizophrenic sympioms: Pathophysiology and clinical implications. Washington, DC: American Psychiatric Press, pp 97-111.

Tandon R, Silk KR, Greden JF, et al (1989a): Positive and negative symptoms in schizophrenia and the dexamethasone suppression test. Biol Psychiatry 25:788-792.

Tandon R, Mazzara C, DeQuardo J (1989b): The DST and outcome in schizophrenia. Am J Psychiatry 146:1648-1649.

Tandon R, DeQuardo J, Goldman R, Craig K, Mazzara C (1990): Psychotic phasic and deficit enduring subtypes of negative symptoms. Biol Pschiary 27:101-102A.

Targum SD (1983): Neuroendocrine dysfuncuon in schizophreniform disorder: Correlation with six-month clinical outcome. Am J Psychiatry 140:309-313.

Whiteford HA, Riney SJ, Savala RA. Csernansky JG (1988): Dexamethasone nonsuppression in chronic schizophrenia. Acia Psychiatr Scand 77:58-62.

Wik G. Wiesel F-A. Eneroth P, Sedvall G, Astron G (1986): Dexanethasone suppression test in schizophrenic patients before and during neurolepti.- treatment. Acta Psychiatr Scand 74:161167.

Wolkowitz OM, Doran A. Sreier A, Roy A, Pickar D (1989): Specificity of plasma HVA response to dexamethasone in psychotic depression. Psychiatry Res 29:177-186.

Yeragani VK (1990): The incidence of abnormal dexamethasone suppression in schizophrenia: A review and a meta-analytic comparison with the incidence in nomal controls. Can J Psychiatry 35:128-132.

Zhou D, Shen Y, Shu L, Lo H (1987): Dexamethasone suppression test and urinary MHPG. SO4 determination in depressive disorders. Bial Psychiatry 22:883-891. 